\title{
Exploring Learning Conversations between Mentors and Associate Teachers in Initial Teacher Education
}

\author{
Luke Jones, Steven Tones and Gethin Foulkes \\ Faculty of Education and Children's Services, University of Chester, Parkgate Road, \\ Chester, UK
}

\begin{abstract}
Purpose - The aim of this paper is to analyse the learning conversations that take place in the context of secondary initial teacher education (ITE) in England. More specifically, it aims to examine the learning conversations that occurred between physical education (PE) subject mentors and their associate teachers (ATs) during a one-year postgraduate programme.

Design/methodology/approach - Self-completion questionnaires and semi-structured interviews, with eleven ATs within a university ITE partnership, were used to explore ATs' perceptions of the learning conversations that occurred between them and their mentors. A process of content analysis was used to identify and analyse themes in the data.

Findings - Meaningful learning conversations are not exclusively based on mentors' feedback on ATs' teaching. The ongoing everyday dialogue that occurs between mentors and ATs has a direct impact on the ATs' teaching and a more indirect effect of nurturing collaborative relationships and providing access to a learning community. Successful mentoring is not realised through an isolated weekly lesson observation of the ATs' teaching. It is an immersive process where the AT and the mentor face the ongoing challenge of exploring aspects of pedagogy and developing a relationship that is conducive to shared learning.

Practical implications - These findings have implications for providers of ITE and more specifically how they approach mentor training. Examining learning conversations, and in particular the more informal everyday dialogue that occurs between the mentor and the AT, may have significant impact on the learning of those who are training to teach.
\end{abstract}

Originality/value - Informal learning conversations are central to the mentoring process. These findings highlight the value of learning conversations and in particular the impact of informal everyday dialogue that may otherwise be overlooked.

Key words - learning conversations, dialogue, dialogic mentoring, physical education, mentor, associate teacher, initial teacher education

Paper type - Case study 


\section{Introduction}

The progress of associate teachers (ATs) (also referred to as trainee or pre-service teachers) completing a one-year postgraduate initial teacher education (ITE) programme is influenced by a range of factors. Most notably, the progress of ATs is influenced by the support provided by their mentor, a more experienced and knowledgeable school-based colleague who provides guidance for the AT during their time at the placement school (Lofthouse, 2017). The mentor plays a central role in the development of the AT as they provide support, encouragement and feedback on teaching. This process inevitably involves a range of conversations that primarily promote the learning of the AT.

Learning conversations between the mentor and the AT take place in different ways. The most obvious interaction occurs after a formal lesson observation, where the mentor provides feedback to the AT on the quality of their teaching. The scheduled lesson observation is a wellestablished and potentially valuable approach within ITE as it provides an opportunity for the mentor and mentee to review progress and identify areas for improvement. Alongside feedback from lesson observations, more informal and unscheduled dialogue also takes place, where the AT and mentor discuss and explore aspects of teaching together (Jones et al., 2018). Over the course of the training year, some mentors have been shown to move towards the latter, a more dialogical two-way approach where understanding is co-constructed through open and meaningful conversations (Bokeno and Gantt, 2000). These conversations have been adopted as a pragmatic response to the increasing teaching load of the ATs, as it would be difficult to find time for the mentor to formally observe and review all lessons. Moreover, these learning conversations were thought, by both ATs and mentors, to be where genuine learning took place (Jones et al., 2018). That is not to diminish the potential value of a formal lesson observation, but to recognise that informal dialogue moves the focus away from what Hobson (2016) called 'judgementoring', where the competency of the AT's teaching is evaluated, and towards less daunting interactions that are more personalised, purposeful and timely (Jones et al., 2018).

Our initial research (see Jones et al., 2018) revealed that both mentors and ATs began to adopt and value more informal dialogic approaches to feedback during the final phase of a one-year physical education (PE) ITE programme. We examined the emergence and development of a dialogic approach but did not consider the nature and impact of the dialogue itself. Our findings drew attention to the nature of the conversations that ATs and mentors have about learning and to the paucity of research in this area, particularly within the context of teacher education and 
even more so within PE teacher education. As such, the present paper aims to develop a more detailed understanding of informal dialogic mentoring conversations. More specifically, it draws on data gathered from one-to-one interviews with PE ATs about the learning conversations that they perceive to have had the most impact on their development as teachers. It aims to identify where and when the learning conversations with their mentors take place; to examine what is said and how it is said; and finally, to understand the impact of learning conversations on the AT and their teaching.

\section{Literature Review}

\section{Mentoring within a community of practice}

A community of practice is a network of people who are bonded together by mutual interests and a shared motivation to learn from, and engage in, collective endeavour (Lave and Wenger, 1991). Within a school community, mentors and ATs can foster a sense of joint identity and trust, as they organise around a common aim or activity. ATs' inclusion and involvement in this community of practice is not fixed, as it changes and advances over time. As individual participants develop competence and become more actively engaged in more complex ways, they move from legitimate peripheral participation to occupying a more central position within a community of practice. Mentors are powerfully positioned to support the movement of ATs from being peripheral participants to more established members of their community of practice. Shields and Murray (2017) noted that mentors provide different types and degrees of support to new teachers, and that this influences their emerging professional identity as legitimate members of the department or whole-school community.

The acceptance and greater inclusion of ATs within a school community is a social process that is influenced by the mastery of knowledge and skills in that particular context (Lave and Wenger, 1991). The situated learning that occurs within a community of practice is founded on social interactions and collaboration and enables ATs to 'speak' as legitimate members of the community. D'Souza (2014) examined the support for new teachers as they establish themselves within a developing community of practice. She found that the design of support within a trusting relationship was critical for new teachers, and that professional relationships were best developed through non-judgemental approaches. 


\section{Dialogic mentoring}

Bokeno and Gantt (2000) described the mentoring process as being either monological or dialogical, with the former being reliant on the expert mentor directing the AT towards a clearly defined end point. In contrast, dialogic mentoring reframes the relationship between the mentor and the AT by moving away from a hierarchical expert-novice model where ATs are positioned as more passive recipients of knowledge (Bokeno and Gantt, 2000). In a dialogic model, mentors and ATs work together to extend their understanding (Lofthouse and Wright, 2012). Mentors are not providers of information about teaching; rather, their role is to work alongside ATs to promote thinking, innovation and discovery (Nahmad-Williams and Taylor, 2015). When adopting this shared approach, the process is led by the mentor as they help the AT to reflect on their teaching. The AT has more ownership, as they are empowered to choose the areas to investigate and set their own targets for development.

According to Bokeno and Gantt (2000), successful dialogic mentoring is built on meaningful two-way conversations where the mentor and the AT value and respect each other's views. Each is a willing participant who wants to contribute and learn from the other (Senge, 1990), with greater support evident when the personalities of the mentor and AT are matched (Menges, 2016). In this way, mentors and ATs form a collaborative and trusting partnership that promotes reflection and open discussion on relevant aspects of pedagogy. The learning conversations at the heart of dialogic mentoring are thought to have genuine value as a means of stimulating and extending thinking (Alexander, 2008; Lofthouse, 2017). The joint experience of dialogue is considered to be mutually productive (Nahmad-Williams and Taylor, 2015) as open discussions can promote shared thinking and provide a space for new thoughts and insights to emerge (Isaacs, 1993; Senge, 1990). Moreover, the discursive aspect of dialogic mentoring may have particular pedagogical value, as Stoll and Finks (1996) claimed that good teachers become better teachers by talking about their learning.

\section{Informal dialogic mentoring}

Dialogic mentoring can be used formally within ITE as part of the conventional practice of providing systematic lesson feedback. Mentors are routinely required to observe and review lessons, and the latter can be more of a two-way discussion about learning, rather than the mentor adopting a monological approach where they simply provide information to the AT. In addition, dialogic approaches can also be used informally by the mentor. They can engage in regular, unplanned, unscheduled learning conversations with ATs, where there is less formality 
or adherence to the conventions of criterion-based approaches. This is a more spontaneous and personalised method, where dialogue flows from the daily shared experiences of the mentor and the AT, rather than from scheduled lesson observations.

While informal mentoring is not a standalone process (Du and Wang, 2017), informal dialogue is recognised as an important part of the mentoring process (James et al., 2015). ATs are thought to be more satisfied with mentors who adopt informal approaches (Ragins and Cotton, 1999), and outcomes of mentoring programmes are considered more successful when they include informal dialogue (Clutterbuck, 2005). Moreover, McNichol (2018) reported that those ATs who were graded 'outstanding' at the end of their ITE year perceived informal day-to-day discussions about learning to be equally important to their progress as feedback received from conventional lesson observations.

One key aspect of informal dialogic mentoring is the development of positive relationships, as this approach ostensibly links 'teaching talk' and 'social talk' (Talbot et al., 2017). Bentley et al. (2017) found that those who were learning to teach developed positive relationships with their mentors over the duration of their yearlong school placement. Similarly, Gordon (2017) claimed that mentoring creates a "growth-in-connection" (p. 27) between the AT and mentor. This is important as when meaningful relationships are established, ATs can gain insight, knowledge, wisdom and also friendship and support from their mentors (Inzer and Crawford, 2005). Put simply, informal learning conversations seemingly promote a strong social bond that allows the AT to gain access to the mentor's resources (Risser, 2013).

\section{Learning conversations}

An informal dialogic approach is built on the regular, unplanned learning conversations that occur between the mentor and the AT. Less is known about the actual nature of these social interactions, but they do have the potential to promote the progress of the AT. Davis and Fantozzi (2016) reported that ATs wanted conversations that not only focused on their technical development as a teacher, but also provided emotional support. They also noted the AT's preference for these conversations to take place away from the 'heat of the classroom'. Similarly, Bentley et al. (2017) suggested that when positive relationships have been established, more informal conversations are likely to take place in different locations and at different times in and around the school. 
This paper examines the learning conversations that occurred between the mentor and the AT in a PE context. It explores ATs' experiences of what they perceived to be meaningful learning conversations, those memorable and influential interactions that have had most impact on their development as teachers.

\section{Methods}

A total of 11 ATs took part in the study during the final phase of their one-year postgraduate teacher education programme. A purposive sampling method was used in the selection of participants (Roberts, 2009), with the inclusion criteria being based on whether or not the ATs were learning to teach PE. As such, all participants were immersed in teacher education and were well placed to reflect in detail on the specific nature and impact of the learning conversations that they had engaged in with their mentors. A convenience sampling method (Roberts, 2009) was also used as participants were studying at the authors' institution and were recruited, in part, for their proximity and availability. While this made data generation convenient, the sample represents a single case of one institution in the north-west of England. Finally, all PE ATs at the authors' institution were invited to participate in the study, and all agreed to do so. To limit the possibility of coercion and bias, recruitment and data generation were undertaken by members of the research team who were not previously known to the ATs.

The study used self-completion questionnaires and one-to-one interviews with ATs to gather data on the nature of the learning conversations that occurred between themselves and their mentors. Self-completion questionnaires were completed once a week over a five-week period towards the end of the one-year postgraduate programme. At the end of every week, ATs were prompted to record a learning conversation that occurred between them and their mentor. The self-completion questionnaires asked ATs to recall the nature and content of the conversation, to identify where and when the conversation occurred and to explain the impact, if any, of the conversation on their progress. Self-completion questionnaires allow respondents to work independently and record their answers to simple and easily understood questions (Denscombe, 2017). In this research, their repeated use over a five-week period was valued as a convenient means of capturing transient experiences before memory recall problems set in (Bryman, 2012). While self-completion questionnaires are easy to administer over a period of time, there is a risk of questionnaire fatigue as respondents lose enthusiasm and begin to drop out or provide less complete data. This can be overcome by explaining expectations beforehand, making the demands of the task realistic and by issuing a weekly reminder (Denscombe, 2017). 
Over the five-week period of data generation, there were seven non-completions, with 48 written learning conversations being recorded by the 11 ATs in all.

A further limitation of self-completion questionnaires is that while they offer a convenient means of generating data, the respondents may not have understood the questions properly or replied with sufficient clarity or detail (Denscombe, 2017). As such, semi-structured interviews were undertaken at the end of the five-week period so that the ATs could clarify and elaborate on their initial responses and provide greater insight into their personal experiences of ATmentor learning conversations. Semi-structured interviews are a well-established means of generating qualitative data. The standardised nature of the questions allows for relatively easy comparison of data generated by different respondents at different locations (Bryman, 2012). Moreover, there is sufficient latitude for the interviewer to move away from the standardised questions and explore new themes as they emerge. This allows the interviewer to examine areas of interest, to clarify complex issues and to uncover a level of detail that may otherwise have remained hidden (Gratton \& Jones, 2010).

In this study, the use of self-completion questionnaires allowed ATs to recollect and record learning conversations while they were fresh in the mind. The one-to-one interviews allowed for further reflection on these conversations and enabled a greater depth of detail to emerge. It is thought that using multiple approaches, more specifically revisiting self-reported data through semi-structured interviews, enhances the validity of the findings and allows for rich descriptions to emerge (Creswell \& Creswell, 2018). By adopting this approach, the interviewer was able to capture nuances beyond superficial comments and develop a deeper level of detailed understanding about the nature and impact of learning conversations.

The interview with each AT were audio recorded and transcribed and organised alongside the initial data from the self-completion questionnaires. A process of content analysis was then used to identify themes in the data. Content analysis is a systematic and logical approach to quantifying the content of a text. It begins with the identification of key words, which are then coded and organised into categories. The frequency with which these key words occur is used to guide a more sophisticated analysis of the text in an attempt to understand and explain the pattern of response (Denscombe, 2017). 
Content analysis is thought to be a clear and repeatable approach to analysing written communication. It is a process that reveals the values and ideas that are contained within a text and is an effective approach for examining data, identifying themes and interpreting findings (Gratton and Jones, 2010). The following 'Findings' section examines the themes that emerged from the data, with individual ATs identified by a number (AT1-AT11) reflecting their place in the sequence of interviews.

\section{Findings}

Where and when did the learning conversations take place?

When ATs recalled the meaningful learning conversations that they had engaged in with their mentors, they also located where and when they took place. The most common locations for learning conversations between the AT and the mentor were the different teaching spaces that were used during the school day. Thirty-eight percent of the conversations took place in teaching spaces (i.e. the playing field, classroom, sports hall, gym and fitness suite), while a further 14 percent took place when moving between learning spaces, often when supervising the return of pupils to the changing rooms at the end of a lesson. Thirty percent of learning conversations took place in the PE office, a small departmental staff room used solely by the school's PE teachers, but often as part of a conversation that had started elsewhere:

We started as we got back to the changing rooms. Then when we got back to the PE office she carried on and some of the other staff jumped in as well and gave additional ideas even though they hadn't seen the lesson. (AT4)

Finally, a smaller number of conversations were conducted in more disparate locations in and around the school (i.e. the staff room, minibus, form room, school refectory, store cupboard and schoolyard). It would seem that while learning conversations mainly occurred in the spaces and places commonly occupied by the PE staff, they did not necessarily need to be limited to these areas. The informal nature of the dialogue between the AT and the mentor conveniently allowed for these conversations to take place in different locations in and around the school.

A similar pattern emerged in relation to the timing of these conversations. Around two thirds of the learning conversations between the ATs and the mentors took place at the time of the lessons that the ATs were teaching. Eighteen percent of the conversations occurred either before or during the lesson and were often seen as a way for the mentor to make minor 
adjustments to the AT's planning or teaching and positively affect the outcome of the lesson. One AT explained how this worked in practice: "Mine's like immediate ... like yesterday she said in the middle of the shot-put lesson, before the next throw rather than doing this, do this. I did it and it worked better with them straight away" (AT6). That said, most of the learning conversations (44 per cent) took place immediately after the lesson when the ATs and mentors were in the teaching space, putting equipment away and moving back to the changing rooms or the PE office: "The immediate feedback is more meaningful. It's that helpful dialogue, maybe when you're walking back to the changing rooms after your lesson" (AT4). The remaining third of the learning conversations occurred before, during and after the school day. There was a relatively even distribution here, with a small number of more meaningful conversations occurring before school, during form time, at break time, over lunch, during a lunchtime extracurricular club, in a free lesson, at the end of the day and finally, when travelling to an after-school fixture.

Meaningful interactions were seemingly centred on the ATs teaching. They mainly occurred in the teaching space at the end of the AT's lesson, but also commonly continued while pupils were supervised until the lesson was concluded. That said, learning conversations could and did occur in different places and at different times throughout and beyond the school day. One AT captured the thoughts of many in saying, "You know how busy your mentor's time is, so you talk whenever it's convenient and you've got a quiet five minutes together" (AT1).

\section{What was said and how?}

When ATs were asked about the content and nature of the more memorable learning conversations that they had had with their mentors, four clear types of interaction emerged: discussion, praise, instruction and questioning. While some learning conversations included two or more of these types of interaction, the most common form of valued communication was a two-way discussion. Over half (54 percent) of the ATs primarily identified their experience of a meaningful learning conversation as a two-way informal discussion with their mentor about aspects of pedagogy. This discussion may have involved aspects of praise, instruction and questioning, but crucially, the AT felt that they were contributing to the learning conversation, rather than merely being a more passive recipient of information. One AT described what was said in a typical discussion with his mentor: 
I had one conversation that was a bit of a light bulb moment. I'd led a starter activity and then wanted them in ability groups for the next activity. He'd gone 'right, okay, draw it out, but adapt it so your starter is also in ability sets. How can you adapt it so you're keeping the same groups and it's allowing differentiation?' I said, 'I'm not sure', and he said, 'well why don't you ...?' and before he said it I went 'actually, could you not start them at different points?' and he went 'yeah, good idea, let's try it'. I was really pleased. He was encouraging me to come up with my own ideas, pushing me to be more independent and more reflective. (AT3)

While two-way discussions were most commonly referred to, ATs also described one-way interactions as being meaningful learning conversations. Around a fifth (19 percent) of the learning conversations were centred on praise, where the mentor would recognise the success or progress of the AT. The praise could be more generic: "That was a really good lesson. They're a really tricky group to teach and you handled it really well” (AT7). Or it could be more specifically focused on one particular incident:

Loved it when you told Neil to move before I came into the lesson and when I came in he tried to tell me what had happened and you stopped him before he could even say anything. Showed that what you say goes. Loved it! (AT11)

A similarly one-way interaction, that positioned the mentor as the expert and AT as the novice, was also seen when the learning conversation took the form of clear instructions. In a few instances (15 percent), the AT described a meaningful learning conversation as an interaction where the mentor told them in a direct manner what they should do in relation to their teaching. This was typically a short instruction: "A group like that, wait for quiet before talking” (AT2). And by its very nature, this type of instruction could be given during a lesson: "It was a little tweak, he just said 'push the more able, go back and ask them to elaborate and add more detail'" (AT5). It was also clear that this type of interaction was more likely to occur at the beginning of the training year when the AT was seen to need more instruction. One AT noted the change and movement away from a one-way instruction:

Everything I got in the first few months I thought was gold dust. But then as I got more experienced and confident I thought no I'm doing it my way. I thought I've found my 
feet. Not to say I didn't want to listen to others, more that I had more confidence and was encouraged to have my say. (AT2)

This developing confidence was a clear theme that emerged as ATs realised that they could also contribute to discussions about teaching and learning:

They are the experienced teachers. They know more, but we bring new ideas to the table too. I think it's finding the balance of them listening to and trusting our new ideas, because that empowers you and makes you believe in what you're doing. (AT9)

Finally, a small number (12 percent) of more meaningful learning conversations were described by ATs as being questions posed by the mentor. This was not understood to be a two-way discussion based on a question and response, but more of a challenge for the AT to think, reflect and find their own answers. As such, one AT was asked, "Can you go away and think about ways you could challenge those high ability pupils?" (AT7). While another was similarly asked, "Can you direct different types of questions at the lower and higher ability to try and involve and challenge everyone in the class? Just have a think about how you could do that for your next lesson" (AT6).

The more meaningful conversations that ATs had with their mentors were described as being primarily based on either discussion, praise, instructions or questions. A two-way discussion was most commonly regarded as being a valuable conversation, but this tended to feature more towards the end of the programme where ATs were more confident and established in their teaching.

\section{What impact did learning conversations have?}

When assessing the impact of the learning conversations, there was a clear distinction between cognitive and affective outcomes. A little over half (53 percent) of the outcomes noted by ATs related to cognitive aspects of learning. The conversations with mentors had made them think (16 percent) about their teaching approaches, had provided ideas (24 percent) on how they could improve in the classroom or had developed their knowledge and understanding (13 percent) of the teaching process. "It made me think. I recognised the reasoning behind the feedback and agreed that I will try and adopt that technique" (AT6). The remaining comments (47 percent) made by ATs about the impact of learning conversations related to affective 
aspects of learning. Around a fifth (21 percent) of the comments noted the positive impact of the interaction, a smaller number (15 percent) of ATs felt that they gained confidence from speaking with their mentors, while a tenth (11 percent) felt encouraged, reassured or inspired. "I felt positive, it allowed me to stay focussed, determined and reassured me that I was doing a good job and my effort isn't going unnoticed" (AT5).

There was also a clear correlation between what and how something was said and the impact it had on the AT. When learning conversations were based on instructions and questions, the impact was primarily cognitive. They were shown to provide ideas and to make ATs think. One AT was told to implement specific aspects of the school policy for rewarding good behaviour. She noted that this "gave me ideas and made me reflect on how to create a positive learning environment" (AT2). Similarly, another AT was challenged to think about extending his teaching:

I thought I was the man again ... but then he's said 'no, no, you could look to change this ...' Forever ongoing isn't it! I felt I'd smashed it, but he was always moving the goalposts and saying, 'great, but how can you do more?' (AT11)

Conversely, when learning conversations were based on praise, the impact was overwhelmingly affective; it built confidence, reassured and encouraged ATs. One AT received praise for his use of creative resources to engage learners and promote active learning. He explained that this learning conversation "built my confidence. It encouraged me to use similar resources in the future and to try different approaches" (AT1). This reaction to praise was enhanced when the mentor recognised the AT's specific expertise and asked them for advice:

I think she trusted me and because it was football, maybe thought that I knew more than her. Which was a nice feeling to be honest. A really nice feeling to know that she respected me enough to ask for help. It really builds your confidence. (AT2)

When learning conversations were described as discussions, the impact on ATs was far more varied. The greater complexity of a two-way discussion meant that a wider range of cognitive and affective outcomes were noted by ATs. These discussions were commonly described as being positive. They provided insight and ideas, prompted ATs to think and reflect but also supported ATs and promoted their confidence. In addition, two-way discussions were shown 
to impact on the relationship between the mentor and the AT. One AT explained the ongoing impact of discussions by saying that initially he was "happy that I'd got it from him nudging me a bit and didn't have to have him tell me exactly what to do" (AT3). The ideas that emerged from the discussion were then incorporated into the AT's teaching: "I used a similar sort of activity next week as a starter exercise and it worked", which made him "feel more confident in my teaching, definitely" (AT3). Moreover, this success also influenced his relationship with his mentor: "It brought me quite close to my mentor in terms of respecting him and being thankful to him. He keeps encouraging me to go higher and higher and be the best I can" (AT3). Finally, the AT also noted how the mentor reacted to this outcome: "He knows the effort he's putting in and can see the impact. I guess he's reaping the rewards of that. I think he enjoys it and enjoys seeing how I progress" (AT3).

Learning conversations were shown to have had cognitive and affective outcomes, which in turn impacted the AT's teaching and the relationships that they had with their mentors. The relationship itself was thought to be the foundation on which the ATs' ongoing progress was built: "You can't underestimate the importance of the relationship, you just have to know that someone's got your back. It's so important for your development and your confidence" (AT6). The role of learning conversations in fostering a rapport with mentors was clear when ATs reflected on their experiences, with one noting that "you need that dialogue between you", while another similarly claimed that "you need that informal feedback ... that informal feedback is just essential" (AT1). The learning conversations were thought to be fundamentally important to the teaching of the AT and to the development of a trusting and supportive relationship with the mentor: "I think it all comes through those informal chats" (AT2).

\section{Discussion}

\section{Immediate and immersive}

The learning conversations that are valued by ATs are those that are mainly centred on their teaching. ATs value these conversations as they are directly focused on a specific teaching episode and provide an opportunity for them to learn from a tangible experience while also receiving support and encouragement. This coincides with some of the established thinking around feedback. Coe et al. (2014, p. 64) suggested that "the best feedback to guide the pursuit of effectiveness is to focus on student progress". This advice encompasses the idea of the mentor being focused on the task, with specific feedback being directly related to the intended learning outcomes. This view is echoed by James and Pollard (2011) who noted that assessment 
should be congruent with learning and that feedback should be designed to advance learning in relation to intended outcomes. Hattie (2011) similarly stated that task-based feedback includes positive reinforcement, correcting work and clarifying targets around explicit criteria; but he adds to this by acknowledging the value of further feedback on the process of learning and the ability to self-regulate. Ko et al. (2014) took this further and pre-empted some of the findings of the current study. They noted the emotive and cognitive aspects of feedback and, as such, suggested that it should always be positive and constructive, to build confidence and foster interest, while also including prompts that ensure success. The learning conversations that the ATs identified as being most meaningful were often those that formed part of the lesson feedback. They were valued for their cognitive and affective impact; they promoted ideas and thinking while also allowing the AT to feel happy, encouraged and empowered in their teaching. This confirmed the conclusions of Davis and Fantozzi (2016), namely, that ATs value the technical and emotional support of their mentor.

The support provided by mentors often occurred immediately after the AT's teaching. The discussion took the form of lesson feedback and related directly to the aspects of pedagogy that had emerged from the lesson. That said, it was also clear that a significant number of the more meaningful learning conversations occurred away from the lesson, both in time and distance. These learning conversations could relate to the teaching experiences of the mentor and the AT but could also include an 'offline' aspect where the discussion moved away from teaching and learning. The informality of these learning conversations merged 'teaching talk' and 'social talk' (Talbot et al., 2017) and allowed for a "growth-in-connection" between the mentor and the AT (Gordon, 2017, p. 27). These learning conversations may not have been directly focused on teaching and learning, and yet they were thought to be important for the teaching and learning of the AT. They allowed for the gradual development of positive relationship and the formation of a social bond that allowed the ATs access to the knowledge and support of the mentor (Inzer and Crawford, 2005; Risser, 2013) and move to a more central position within the community of practice (Shields and Murray, 2017). Moreover, these learning conversations occurred at different times and in different places throughout and beyond the school day. Mentoring, it seems, is not a once-a-week interaction where the AT's lesson is discussed and analysed. According to the ATs, meaningful learning conversations, in whatever form, occur throughout the school placement. Successful mentoring is seemingly an immersive process, where the AT and the mentor are continuously challenged - more obviously by the demands of planning and teaching effective lessons, but also by the need to develop a relationship that 
is conducive to shared learning. Timperley et al. (2007) noted the value of a learning culture within a school community and also referred to the continuous professional learning that occurs as the AT responds to ongoing mentor feedback. That said, in this instance, the ATs were recognising the additional value of everyday interactions, as they allowed them to move from the periphery and be more active participants in a professional learning community.

\section{Varied and valued}

The everyday informal dialogue that is valued by the ATs takes many different forms. These learning conversations can be more of a one-way interaction, taking the form of praise, questions or instructions from the mentor. Ko et al. (2014) argued that mentor-AT interactions should be adapted to cater for the varying needs of different individual learners in different circumstances. Direct instructions and praise were valued by the ATs, particularly at the start of the one-year programme as they provided clarity and confidence. Over time, ATs found their voice and were more likely to contribute to a professional dialogue in an informed manner (Lave and Wenger, 1991). This reflected previous findings by Jones et al. (2018) that illustrated the developmental nature of learning conversations. Mentors typically begin by using praise and instructions to establish more basic and generic aspects of pedagogy, but over time, there is a shift towards dialogue that is more personalised and challenging, as it asks the AT to think for themselves about increasingly complex aspects of teaching and learning.

Overall, it was this type of two-way learning conversation that ATs most frequently identified as being meaningful. They may have initially been reluctant to contribute, but as they developed their understanding and confidence, ATs came to value the opportunity to share their thinking and to be listened to. This suggests a positive correlation between the effectiveness of the AT and the professional learning community in which they worked. ATs recognised the value of a trusting and supportive learning environment (Coe et al., 2014; Hobson, 2016; Shields and Murray, 2017; Timperley et al., 2007). Indeed, Senge (1990) noted that the most effective learning conversations occur when all of those involved are willing to share their own thinking while also allowing their understanding to be informed and challenged by the views of others.

Open dialogue seemingly emerges as the mentor and AT develop a trusting and non-threatening reciprocal relationship. This in part is influenced by the recognition, by both the mentor and the AT, that the AT also brings ideas and can influence the learning and understanding of the 
mentor and others in the department (Hurd, 2007). The organisation of the postgraduate training year allows for the transfer of ideas from one setting to another. The ATs will typically experience the teaching of PE at the university and engage in learning conversations with lecturers and other ATs who are working in different schools. They also have two extended placements in secondary PE departments and spend a shorter amount of time in a primary school and in other educational settings. As such, ATs become the conduit for the transfer of ideas among schools, and this can give them currency when they are working with their mentor. The learning of knowledge and skills that is situated in one context can have value when transferred to another school community of practice (Lave and Wenger, 1991). In this way, exposure to a range of educational experiences and ideas can arm the AT and better prepare them not only for teaching, but also for establishing a reciprocal relationship with their mentor, where they are valued for their ability to contribute and co-construct ideas.

\section{Impact and influence}

The type of learning conversation was directly related to its impact on the AT. Largely oneway interactions that were more consistent with monological mentoring approaches (Bokeno and Gantt, 2000) provided ideas, either through direct instructions from the mentor or emotional support through praise. In contrast, while the impact of two-way conversations on ATs also included cognitive and affective outcomes, the greater complexity of these interactions brought a wider range of responses. Dialogic approaches (Bokeno and Gantt, 2000) worked best when the ATs were further into their school placement, when they were more able to find their own solutions rather than have problems resolved for them.

These two-way learning conversations had further repercussions. They typically allowed for the co-construction of ideas in response to the challenges associated with improving the teaching of the ATs. As the ATs began to adopt these ideas into their lessons and experience the favourable impact on pupil learning (Timperley et al., 2007), they increasingly valued the guidance of the mentor. In this way, the ongoing progress of the AT helped develop a trusting and supportive relationship, as the time and effort invested in these learning conversations was shown to have a worthwhile outcome. In addition, as confidence developed in the ability of the partnership to find appropriate solutions to teaching problems, the focus occasionally shifted towards the teaching of the mentor (Lofthouse and Wright, 2012). The mentors seemingly provided support without expecting any benefit in return but were also keen to learn from the ATs and advance their own practice when the opportunity presented itself. The mentors' 
obvious desire to improve was in itself valued by the ATs as it provided a model of continual learning and helped establish a professional learning community (McGraw and Davis, 2017). Moreover, the mentors' willingness to listen to the ATs and learn from their shared learning conversations was shown to be a pivotal moment. The ATs were initially surprised and excited by this reciprocal aspect of learning, but often returned to these moments as confirmation of their own ability. When the mentor adopted an AT's ideas and applied them successfully in their own teaching, it helped establish the AT's self-perception as a respected and effective teacher.

\section{Conclusions}

The development of ATs is commonly understood to benefit from learning conversations where mentors provide feedback that recognises effective aspects of the AT's teaching and also helps them to identify the next steps towards further improvement (Hattie, 2011; Timperley et al., 2007). These learning conversations are seemingly more effective when mentors adopt a more dialogic approach (Bokeno and Gantt, 2000) and engage the AT in a two-way conversation that promotes a greater level of independent thinking. In addition, more informal two-way learning conversations that occur away from lessons as part of everyday discussions are valued by ATs. They are thought to promote a reciprocal and collaborative relationship (Gordon, 2017) that allows the AT access to their mentor's individual resources and to their wider learning community. Moreover, these learning conversations provide opportunities for the AT to share their emerging ideas and experience their constructive impact on the knowledge and teaching of their mentor.

The impact of this research may be most valuable for providers of ITE and, in turn, for those mentors and other teachers who work with ATs every day in schools. The relationship between the mentor and AT is self-organising. Some of their practice conforms to the expectations of the university provider, but mentors and ATs control their own interactions. A trusting reciprocal relationship does not appear as soon as the AT starts their school placement; rather, it develops over time. Many such relationships may be best left to develop on their own, while others may benefit from some external attention, providing this does not overwhelm the participants. What is clear from an understanding of communities of practice (Lave and Wenger, 1991) is that those seeking to train mentors, to develop their understanding of collaborative reciprocal relationships, must aim to do so from the inside, rather than attempting to manipulate a relationship from the outside. As such, ITE providers should work more closely 
with individual mentors rather than only providing generic group training. A more personalised, bespoke approach to mentor training would allow mentors to discuss the nature of the dialogue that they share with their AT. They could review how they provide time and space for collaboration, how they engage in regular two-way dialogue and how they foster a more trusting and reciprocal relationship with their AT. These individual mentor training conversations would recognise the context of the mentor and draw attention to the value of informal learning conversations. Similarly, ITE providers should attend some PE department meetings to allow other teachers to discuss how their participation contributes to the development of the AT. Merely raising awareness of their role would arguably sensitise teachers to the nurturing value of informal everyday conversations. Mentor training that is situated inside the department would help legitimise it as a place for sharing and creating ideas and would promote the active involvement of the AT. It may also develop a deeper understanding of the needs and motives of the mentor.

Informal learning conversations have a notable impact on the holistic development of ATs. Further research might profitably be undertaken to analyse mentors' perception of learning conversations and how relationships are established through informal dialogue.

\section{References}

Alexander, R. J. (2008), Towards Dialogic Teaching: rethinking classroom talk, Dialogos, York, United Kingdom.

Bentley, E., Workman, M., and Overby, A. (2017), "Being "adopted" into a teaching community: Exploring mentoring relationships in a yearlong field placement", International Journal of Mentoring and Coaching in Education, Vol. 6 No. 3, pp. 228241.

Bokeno, R. and Gantt, V. (2000), "Dialogic mentoring: core relationships for organizational learning”, Management Communication Quarterly, Vol. 14 No. 2, pp. 237-270.

Bryman, A. (2012), Social research methods: fourth edition, Oxford University Press, Oxford, United Kingdom.

Coe, R., Aloisi, C., Higgins, S. and Major, L.E. (2014), What makes great teaching? Review of the underpinning research, Project Report. Sutton Trust, London, United Kingdom.

Clutterbuck, D. (2005), "Formal v Informal mentoring: Time to shift the debate”, available at: http://scottishmentoringnetwork.co.uk/assets/downloads/resources/formal-v-informalmentoring.pdf (accessed 1 July 2018). 
Creswell, J. and Creswell, D. (2018), Research design: fifth edition, Sage, London, United Kingdom.

Davis, S.J., and Fantozzi, V.B. (2016), "What do student teachers want in mentor teachers? Desired, Expected, Possible and Emerging Roles", Mentoring and Tutoring: Partnership in Learning, Vol. 15 No.1, pp. 27-41.

Denscombe, M. (2017), The good research guide for small scale social research projects: sixth edition, Open University Pres, London, United Kingdom.

D’Souza, L. (2014), "Bridging the gap for beginning teachers: researcher as mentor", International Journal of Mentoring and Coaching in Education, Vol. 3 No. 2, pp. 171187.

Du, F. and Wang, Q. (2017), "New Teachers' perspectives of informal mentoring: quality of mentoring and contributors", Mentoring and Tutoring: Partnership for Learning, Vol. 25 No. 3, pp. 309-328.

Gordon, E.J. (2017), "Exploring the dyad: the relationship establishment between a novice physical education teacher and his mentor", Mentoring and Tutoring: Partnership in Learning, Vol. 25 No. 1, pp. 27-41.

Gratton, C. and Jones, I. (2010), Research Methods for Sports Studies, Routledge, London, United Kingdom.

Hattie, J. (2011), "Feedback in schools", in Sutton, R., Hornsey, M.J. and Douglas, K.M. (Eds.), Feedback: The communication of praise, criticism, and advice, Peter Lang Publishing, New York, NY, pp. 1-14.

Hobson, A.J. (2016), “Judgementoring and how to avert it: introducing ONSIDE Mentoring for beginning teachers", International Journal of Mentoring and Coaching in Education, Vol. 5 No.2, pp. 87-110.

Hurd, S. (2007), The Impact of Trainee Teachers on School Achievement: a review of research, Training and Development Agency, London, United Kingdom.

Isaacs, W. N. (1993), "Dialogue, collective thinking, and organizational learning", Organizational Dynamics, Vol. 22 No. 2, pp. 24-39.

Inzer, L.D. and Crawford, C.B. (2005), “A Review of Formal and Informal Mentoring: Processes, Problems, and Design”, Journal of Leadership Education, Vol. 4 No. 1, pp. $31-50$.

James, M. and Pollard, A. (2011), “TLRP's ten principles for effective pedagogy: rationale, development, evidence, argument and impact", Research Papers in Education, Vol. 26 No. 3, pp. 275-328. 
James, J., Rayner, A. and Bruno, J. (2015), “Are You My Mentor? New Perspectives and Research on Informal Mentorship", The Journal of Academic Librarianship, Vol. 41 No. 5, pp.532-539.

Jones, L., Tones, S. and Foulkes, G. (2018), "Mentoring Associate Teachers in Initial Teacher Education: The Value of Dialogic Feedback", International Journal of Mentoring and Coaching in Education, Vol. 7 No. 2, pp. 127-138.

Ko, J., Sammons, P. and Bakkum, L. (2014), Effective Teaching, Education Development Trust. University of Oxford.

Lave, J. and Wenger, E. (1991), Situated Learning. Legitimate peripheral participation, University of Cambridge Press, Cambridge, United Kingdom.

Lofthouse, R. (2017), “Improving Mentoring Practices through Collaborative Conversations”, available at: https://www.schooleducationgateway.eu/en/pub/viewpoints/experts/improvingmentoring-practices-.htm (accessed 1 July 2018).

Lofthouse, R. and Wright, D. (2012), “Teacher education lesson observation as boundary crossing”, International Journal of Mentoring and Coaching in Education, Vol. 1 No. 2, pp. 89-103.

McGraw, A. and Davis, R. (2017), "Mentoring for pre-service teachers and the use of inquiryoriented feedback", International Journal of Mentoring and Coaching in Education, Vol. 6 No. 1, pp. 50-63.

McNichol, S. (2018), "Developing the behaviour management skills of pre-service teachers during teacher training: What can we learn from successful trainees?", paper presented at the $9^{\text {th }}$ Teacher Education Advancement Network (TEAN) Conference, 10 -11 May, Birmingham, United Kingdom.

Menges, C. (2016), “Toward Improving the Effectiveness of Formal Mentoring Programs: Matching by Personality Matters", Group \& Organization Management, Vol. 41 No. 1, pp. 98-129.

Nahmad-Williams, L. and Taylor, C.A. (2015), "Experimenting with dialogic mentoring: a new model", International Journal of Mentoring and Coaching in Education, Vol. 4 No. 3, pp. 184-199.

Ragins, B.R. and Cotton, J.L. (1999), "Mentor functions and outcomes: A comparison of men and women in formal and informal mentoring relationships", Journal of Applied Psychology, Vol. 84 No. 4, pp. 529-550. 
Risser, H. (2013), "Virtual induction: A novice teacher's use of Twitter to form an informal mentoring network", Teaching and Teacher Education, Vol 35, pp.25-33.

Roberts, K. (2009), Key concepts in sociology, Palgrave Macmillan, London, United Kingdom.

Senge, P. (1990), The Fifth Discipline: The Art and Practice of the Learning Organization, Currency Doubleday, New York, NY.

Shields, M. and Murray, M. (2017), "Beginning teachers' perceptions of mentors and access to communities of practice", International Journal of Mentoring and Coaching in Education, Vol. 6 No. 4, pp. 317-331.

Stoll, L. and Fink, D. (1996), Changing our schools: Linking school effectiveness and school improvement, Open University Press, London, United Kingdom.

Talbot, D., Denny, J. and Henderson, S. (2017), "Trying to decide... what sort of teacher I want to be - mentoring as a dialogic practice", Journal of Teaching Education, Vol. 29 No. 1, pp. 47-60.

Timperley, H., Wilson, A., Barrar, H. and Fung, I. (2007), “Teacher professional learning and development: Best evidence synthesis iteration", available at: http://www.educationcounts.govt.nz/publications/series/2515/15341 (accessed 1 July 2018). 